\title{
Analisis Kualitas Air Sungai Guna Menentukan Peruntukan Ditinjau Dari Aspek Lingkungan
}

\author{
Dedy Anwar Saleh Pohan¹, Budiyono², Syafrudin ${ }^{3}$ \\ ${ }^{1}$ Program Magister Ilmu Lingkungan Universitas Diponegoro Semarang; email: pohananwar@gmail.com \\ ${ }^{2}$ Jurusan Teknik Kimia Fakultas Teknik Universitas Diponegoro Semarang \\ ${ }^{3}$ Jurusan Teknik Lingkungan Fakultas Teknik Universitas Diponegoro Semarang
}

\begin{abstract}
ABSTRAK
Sungai Kupang adalah salah satu sungai yang mengalir di Kota Pekalongan yang menerima limbah, baik dari industri, pertanian maupun domestik, Perkembangan industri dan pemukiman di sepanjang aliran sungai Kupang telah mempengaruhi kualitas air sungai. Penurunan kualitas air ditandai dengan perubahan warna air dan bau padahal sebahagian masyarakat di pinggiran sungai masih memanfaatkan air Sungai Kupang untuk kebutuhan sehari-hari. Penelitian ini bertujuan untuk menganalisis kualitas air sungai Kupang berdasarkan baku mutu kualitas air sungai menurut PP Nomor 82 Tahun 2001, menghitung beban pencemar Sungai Kupang dan menentukan Status Mutu Air serta merekomendasi upaya pengelolaan kualitas air Sungai Kupang Pekalongan. Pengukuran kualitas air dilakukan pada 6 titik pengambilan sampel. Parameter yang diukur dan diamati adalah parameter Temperatur, TSS, pH, DO, BOD, COD, Kromium dan Phosphat. Untuk analisis Status mutu air Sungai Kupang dengan menggunakan metode indeks pencemaran dan daya tampung beban pencemaran dengan menggunakan metode Qual2 Kw. Hasil penelitian pada kualitas air Sungai Kupang menunjukkan parameter COD di beberapa titik telah melebihi baku mutu. Sedangkan untuk parameter BOD di semua titik telah melebihi baku mutu yang dipersyaratkan. Nilai konsentrasi BOD terendah adalah sebesar 5,75 mg/l, sedangkan nilai BOD tertinggi sebesar $27 \mathrm{mg} / \mathrm{l}$. Kandungan BOD meningkat diduga karena sepanjang aliran sungai yang di mulai dari hulu hingga hilir banyak menerima limbah buangan, sementara berdasarkan status mutu air menunjukkan penurunan kualitas air dari hulu sampai ke hilir sungai, dimana pada bagian hilir telah tercemar ringan. Dan untuk hasil perhitungan beban pencemaran Sungai Kupang dari hulu ke hilir mengalami peningkatan, untuk beban pencemaran konsentrasi TSS adalah sebesar $20.670,334 \mathrm{~kg} / \mathrm{hari}$, sedangkan konsentrasi COD adalah sebesar 16.517,777 kg/hari, dan konsentrasi BOD yaitu sebesar 6.618,643 kg/hari.
\end{abstract}

Kata kunci: Water Quality, Pollution Load, Kupang River

\begin{abstract}
Sungai Kupang is one of the rivers that flow in Pekalongan city that receives the waste, both from industrial, agricultural and domestic, industrial and residential development along the river Kupang have affected the quality of river water. Water quality degradation characterized by changes in water color and odor when sebahagian riverside communities still use river water Kupang for everyday needs. This study aimed to analyze the water quality of the river Kupang based on river water quality standards in accordance with Regulation No. 82 of 2001, calculating the pollutant load Sungai Kupang and determine Air Quality Status and recommend management measures Pekalongan Kupang River water quality. Water quality measurements performed at 6 sampling points. Parameters measured and observed are the parameters of temperature, TSS, pH, DO, BOD, COD, chromium and Phosphate. For the analysis of the water quality of Sungai Kupang status using the pollution index and pollution load capacity using Qual2Kw.

The results of research on water quality of Sungai Kupang shows COD parameter at some point has exceeded the standard quality. As for the parameters BOD at all points have exceeded the quality standards required. BOD value is the lowest concentration of $5.75 \mathrm{mg} / \mathrm{l}$, while the highest value of BOD of $27 \mathrm{mg} / \mathrm{l}$. The content of BOD increased presumably because the watershed is in from upstream to downstream received many waste dumps, while based on the status of water quality showed a decrease in water quality from upstream to downstream, which in part has been lightly polluted downstream. And also for the calculation of pollution loads Kupang River from upstream to downstream has increased, to the pollution load of TSS concentration amounted $20670.334 \mathrm{~kg} /$ day, while the COD concentration is equal to $16517.777 \mathrm{~kg} /$ day, and the BOD concentration is equal to $6618.643 \mathrm{~kg} /$ day.
\end{abstract}

Keywords: Water Quality, Pollution Load, Kupang River

Cara sitasi: Pohan, D. A. S., Budiyono, Syafrudin. (2016). Analisis Kualitas Air Sungai Guna Menentukan Peruntukan Ditinjau dari Aspek Lingkungan di Sungai Kupang Kota Pekalongan. Jurnal Ilmu Lingkungan,14(2),63-71, doi:10.14710/jil.14.2.63-71

\section{PENDAHULUAN}

Sungai Kupang adalah bagian dari Satuan Pengelolaan Daerah Aliran Sungai SWP DAS Pemali Comal. Luas wilayah Sungai Kupang seluas
18.022,193 Ha di Provinsi Jawa Tengah bagian utara yang melintasi 3 Kabupaten dan 1 Kota, yaitu mulai dari yang terluas adalah Kabupaten Pekalongan sebesar 53,88\% (9.708,13 ha), Kabupaten Batang 
$32,04 \% \quad(5.774,51$ ha), Kota Pekalongan 14,06 \% $(2.533,221 \mathrm{ha})$, dan yang terkecil adalah Kabupaten Banjarnegara sebesar 0,04\% (6,332 ha) (BPDAS Pemali-Jratun, 2013).

Sungai Kupang adalah salah satu sungai yang mengalir di Kota Pekalongan yang menerima limbah, baik dari industri maupun domestik, Perkembangan industri dan pemukiman di sepanjang aliran sungai Kupang telah mempengaruhi kualitas air sungai. Lingkungan dapat dikatakan tercemar jika dimasuki atau kemasukan bahan pencemar yang dapat mengakibatkan gangguan pada makhluk hidup yang ada didalamnya (Bahtiar, 2007). Penurunan kualitas air ditandai dengan perubahan warna air dan bau padahal sebahagian masyarakat di pinggiran sungai masih memanfaatkan air Sungai Kupang untuk kebutuhan sehari-hari. Suatu sungai dikatakan tercemar jika kualitas airnya sudah tidak sesuai dengan peruntukkannya. Kualitas air ini didasarkan pada baku mutu kualitas air sesuai kelas sungai berdasarkan Peraturan Pemerintah Nomor 82 Tahun 2001 tentang Pengelolaan kualitas Air dan Pengendalian Pencemaran Air.

Tata guna lahan merupakan bagian penting yang mempunyai pengaruh pada kualitas air sungai. Kemampuan daya tampung air sungai yang telah ada secara alamiah terhadap pencemaran perlu dipertahankan untuk meminimalkan terjadinya penurunan kualitas air sungai (Marfai Aris, 2004). Penggunaan lahan di sepanjang Sungai Kupang yang dapat mempengaruhi kualitas air sungai Kupang meliputi pertanian, permukiman dan industri. Kegiatan pertanian tanaman semusim yang menggunakan pupuk dan pestisida diperkirakan akan mempengaruhi kualitas air sungai melalui buangan dari lahan pertanian yang masuk ke badan air.

Disamping itu, kegiatan masyarakat yang menghasilkan buangan air limbah domestik serta keberadaan industri tekstil dan batik yang membuang air limbahnya ke sungai Kupang akan berpengaruh terhadap kualitas air. Pengelolaan kualitas air dilakukan dengan upaya pengendalian pencemaran air, yaitu dengan upaya memelihara fungsi air sehingga kualitas air memenuhi baku mutu (Azwir, 2006). Penelitian ini bertujuan untuk menganalisis kualitas air sungai Kupang, untuk menghitung beban pencemar Sungai Kupang dan menentukan Status Mutu Air Sungai Kupang Pekalongan serta untuk merekomendasi upaya pengelolaan kualitas air Sungai Kupang Pekalongan.

\section{METODE PENELITIAN}

\subsection{Lokasi dan Waktu Penelitian}

Lokasi penelitian dilakukan di wilayah Kota Pekalongan, dan pengambilan sampel air dilakukan di Sungai Kupang. Sedangkan waktu penelitian dilakukan pada bulan Juni 2015.

\subsection{Material dan Metode}

Materi yang digunakan pada penelitian ini meliputi air Sungai Kupang Pekalongan, sampel air digunakan untuk melihat konsentrasi kualitas air, sedangkan parameter kualitas air yang diukur adalah Temperatur, TSS, pH, DO, BOD, COD, Kromium dan Phosphat. Pengukuran parameter TSS, BOD, COD Phosphat dan Kromium dilakukan di Laboratorium Balai Besar Teknologi Pencegahan Pencemaran Industri (BBTPPI) Provinsi Jawa Tengah. Dan metode yang digunakan dalam penelitian ini adalah metode deskriptif dengan pendekatan kuantitatif.

\subsection{Penentuan Titik Pengambilan Sampel}

Penentuan titik pengambilan sampel air menggunakan "sample survey method", yaitu metode pengambilan sampel dilakukan dengan membagi daerah penelitian menjadi segmen atau titik yang diharapkan dapat mewakili populasi penelitian. Penentuan titik pengambilan kualitas air sungai didasari atas kemudahan akses, biaya maupun waktu dalam penelitian.

Berikut ini merupakan 6 (enam) titik lokasi pengambilan sampel air sungai Kupang, yaitu;

Tabel 1. Titik lokasi penelitian

\begin{tabular}{|c|c|c|}
\hline Titik Lokasi dan Koordinat & & Penggunaan Lahan \\
\hline 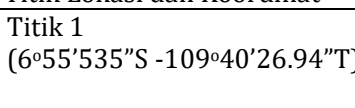 & & $\begin{array}{l}\text { Pada bagian Hulu Sungai di } \\
\text { kelurahan Kuripan Lor (Daerah } \\
\text { pertanian) }\end{array}$ \\
\hline $\begin{array}{l}\text { Titik } 2 \\
\left(6^{\circ} 54^{\prime} 40.46^{\prime \prime} \mathrm{S}\right. \\
\left.109^{\circ} 40^{\prime} 27.00^{\prime \prime} \mathrm{T}\right)\end{array}$ & - & $\begin{array}{l}\text { Di kelurahan Kuripan Lor } \\
\text { (daerah pertanian dan sebelum } \\
\text { daerah permukiman penduduk) }\end{array}$ \\
\hline $\begin{array}{l}\text { Titik 3 } \\
\left(6^{\circ} 53^{\prime} 44.36^{\prime \prime} \mathrm{S}\right. \\
\left.109^{\circ} 40^{\prime} 37.32^{\prime \prime} \mathrm{T}\right)\end{array}$ & & $\begin{array}{lr}\text { Di kelurahan } & \text { Landung Sari } \\
\text { (daerah } & \text { permukiman } \\
\text { penduduk) } & \end{array}$ \\
\hline $\begin{array}{l}\text { Titik } 4 \\
\left(6^{\circ} 52^{\prime} 46.18^{\prime \prime} \mathrm{S}\right. \\
\text { 109॰40'19.40"T) }\end{array}$ & - & $\begin{array}{l}\text { Di kelurahan Pesindon (daerah } \\
\text { permukiman) }\end{array}$ \\
\hline $\begin{array}{l}\text { Titik } 5 \\
\left(6^{\circ} 52^{\prime} 46.18^{\prime \prime} \mathrm{S}\right. \\
\left.109^{\circ} 40^{\prime} 48.20^{\prime \prime} \mathrm{T}\right) \\
\text { Titik 6 } \\
\left(6^{\circ} 52^{\prime} 25.63^{\prime \prime} \mathrm{S}\right. \\
\text { 10940'39.61"T) }^{\circ}\end{array}$ & & $\begin{array}{l}\text { Di kelurahan Krapyak Kidul } \\
\text { (daerah permukiman dan } \\
\text { Industri Batik) } \\
\text { Pada bagian hilir Sungai Kupang } \\
\text { di kelurahan Panjang wetan } \\
\text { (daerah industri) }\end{array}$ \\
\hline
\end{tabular}

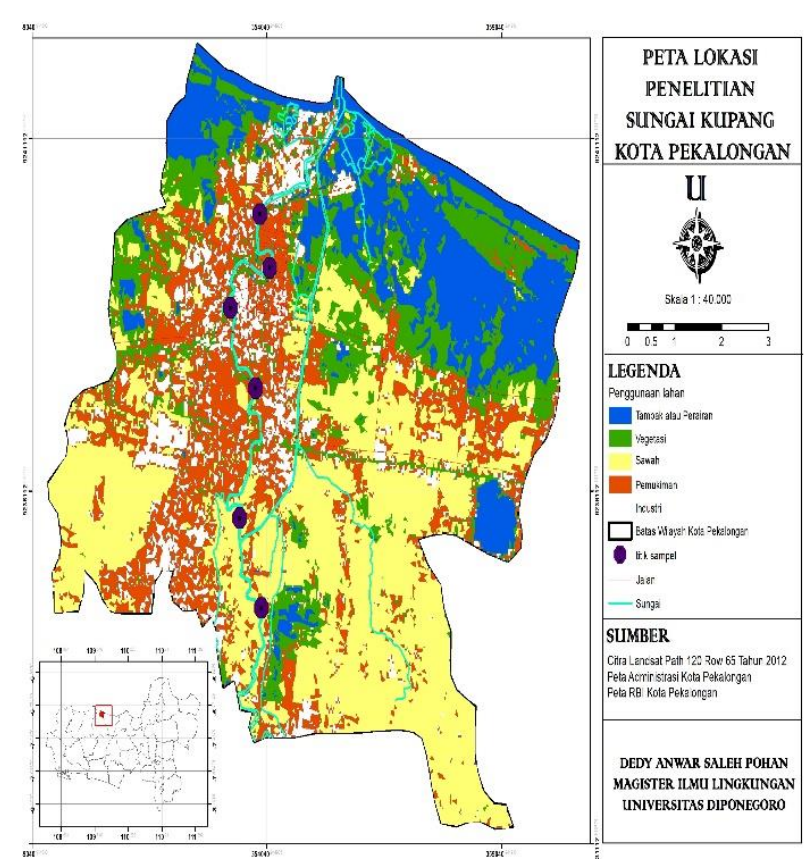

Gambar 1. Peta lokasi penelitian Sungai Kupang 
Pohan, D. A. S., Budiyono, dan Syafrudin. (2016). Analisis Kualitas Air Sungai Guna Menentukan Peruntukan Ditinjau dari Aspek Lingkungan di Sungai Kupang Kota Pekalongan. Jurnal Ilmu Lingkungan,14(2),63-71, doi:10.14710/jil.14.2.63-71

\subsection{Analisa Data}

Analisis data adalah proses telaah dan pencarian makna dari data yang diperoleh untuk menemukan jawaban dari masalah penelitian. Analisis data yang dilakukan meliputi analisis kualitas air, dan analisis beban pencemaran serta perhitungan daya tampung beban pencemaran.

\subsection{Perhitungan Status Mutu Air}

Penentuan status mutu air menggunakan metode Indeks Pencemaran sesuai Keputusan Menteri Negara Lingkungan Hidup No. 115 Tahun 2003 Lampiran II tentang Pedoman Penentuan Status Mutu Air. Untuk mengetahui tingkat pencemaran pada sungai digunakan rumus dibawah ini :

$$
P i j=\sqrt{\frac{\left(C_{i} / L_{i j}\right)_{2 M}+\left(C_{i} / L_{i j}\right)_{2 R}}{2}}
$$

Keterangan;

Lij =Kosentrasi parameter kualitas air yang dicantumkan dalam baku mutu peruntukan air (J)

$\mathrm{Ci} \quad=$ Kosentrasi parameter kualitas air dilapangan

Pij $\quad=$ Indeks pencemaran bagi peruntukan (J)

$\mathrm{Ci} / \mathrm{Lij}) \mathrm{M}=$ Nilai, $\mathrm{Ci} / \mathrm{Lij}$ maksimum

$(\mathrm{Ci} / \mathrm{Lij}) \mathrm{R}=$ Nilai, Ci/Lij rata-rata

Pada metode Indeks Pencemaran digunakan berbagai parameter kualitas air, maka pada penggunaannya dibutuhkan nilai rata dari keseluruhan nilai $\mathrm{Ci} / \mathrm{Lij}$ sebagai tolak ukur pencemaran, tetapi nilai ini tidak akan bermakna jika salah satu nilai $\mathrm{Ci} / \mathrm{Lij}$ bernilai $>1$. Jadi indeks ini harus mencakup nilai $\mathrm{Ci} / \mathrm{Lij}$ yang maksimum. Sungai semakain tercemar untuk suatu peruntukan (J) jika nilai $(\mathrm{Ci} / \mathrm{Lij}) \mathrm{R}$ dan $(\mathrm{Ci} / \mathrm{Lij}) \mathrm{M}$ adalah lebih besar dari 1,0 jika nilai (Ci/Lij)R dan nilai (Ci/Lij)M makin besar , maka tingkat pencemaran suatu badan air akan semakin besar pula.

Metode ini menghubungkan tingkat pencemaran suatu perairan yang dipakai untuk peruntukan tertentu dengan nilai parameterparameter tertentu, seperti ditunjukkan pada Tabel. Berikut ini.

Tabel 2. Hubungan nilai IP dengan status mutu air

\begin{tabular}{cl}
\hline Nilai IP & Mutu Perairan \\
\hline $0-1,0$ & Kondisi baik \\
$1,1-5,0$ & Cemar Ringan \\
$5,0-10,0$ & Cemar sedang \\
$>10,0$ & Cemar berat \\
Sumber: Kep-MENLH NO 115 Tahun 2003
\end{tabular}

\subsection{Perhitungan Beban Pencemaran}

Pada perhitungan beban pencemaran dilakukan dengan menghitung debit air sungai dan memperkirakan beban pencemaran yang meliputi beban pencemaran sungai industri, domestik dan pertanian. Beban Pencemaran Sungai, dihitung dengan menggunakan rumus :

$$
B P S=(C s) j \times \text { Qs } x \mathrm{f}
$$

Keterangan :

BPS = Beban Pencemaran Sungai $(\mathrm{kg} / \mathrm{hr})$

(Cs) $\mathrm{j} \quad=$ Kadar terukur sebenarnya unsur pencemar-j (mg/lt)

Qs = Debit air sungai (m3/hari)

$\mathrm{f} \quad=$ Faktor konversi

\subsection{Metode Qual2Kw}

Penggunaan program QUAL2Kw dapat mengestimasi nilai beban pencemaran pada tiap segmen sungai. Pemodelan dengan menggunakan software QUAL2Kw terlebih dahulu dilakukan pembagian segmen (reach), jarak dan batas sungai, sebagai berikut;

Tabel 3. Pembagian segmen di Sungai Kupang yang Dipergunakan

\begin{tabular}{|c|c|c|c|c|}
\hline Segmen & & Lokasi & & $(\mathrm{Km})$ Jarak \\
\hline Segmen I & Titik 2 & Titik 1 & - & $\begin{array}{r}\mathrm{Km} \\
\pm 8,02- \pm 7,24\end{array}$ \\
\hline Segmen II & Titik 4 & Titik 2 & - & $\begin{array}{r}\mathrm{Km} \\
\pm 7,24- \pm 1,58\end{array}$ \\
\hline Segmen III & Titik 6 & Titik 4 & - & $\mathrm{Km} \pm 1,58$ \\
\hline
\end{tabular}
dalam Perhitungan dengan program QUAL2Kw

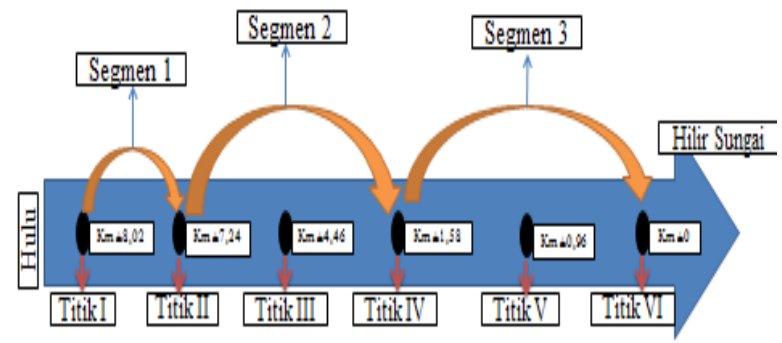

Gambar 2. Pembagian Segmen pada Sungai Kupang

Kemudian input Letak geografis dan ketinggian point sources, withdrawal dan dam, kemudian Klimatologis (temperatur udara, dew point, kecepatan angin, dan tutupan awan), input Hidrologis koefisien kekasaran manning, side slope 1 , side slope 2, lebar dasar sungai, debit di headwater. Dan input Konsetrasi TSS, BOD, COD, DO, pH dan temperatur air pada tiap titik sampling.

Setelah melakukan tahap pegisian data, maka program Qual2Kw dijalankan (running). Program Qual2Kw membuat file output dan input secara otomatis. Untuk melihat Output Tabuler dapat dilihat pada Worksheet WQ output, dan jika melihat Output Grafik dapat dilihat pada Worksheet spatial chart (Ardhani, 2014). Kemudian melakukan Kalibrasi Model.

Kalibrasi model dilakukan dengan kriteria statistik yaitu uji $\mathrm{X}^{2}$ (Kologorov-Smirnov) dimana kriteria kinerja model adalah rata-rata kuadrat simpangan dari residu (beda antara pengukuran lapangan dengan hasil model).

Setelah model dinyatakan diterima atau sesuai dengan keadaan yang sebenarnya, dilakukan simulasi 
untuk melihat kadar parameter pencemar disepanjang sungai. Kadar parameter bahan pencemar diamati pada setiap penggal dan digunakan sebagai dasar untuk menghitung beban pencemaran sungai. Selanjutnya dilakukan simulasi jika kondisi kadar parameter pencemar disepanjang sungai memenuhi baku mutu untuk mengukur daya tampung beban pencemaran sungai (Ardhani, 2014).

\section{HASIL DAN PEMBAHASAN}

\subsection{Kualitas Air}

Hasil analisis kualitas air pada titik yang berbeda disajikan pada tabel 4 sebagai berikut;

Tabel 4. Hasil analisis kualitas air Sungai kupang

\begin{tabular}{|c|c|c|c|c|c|c|c|c|c|c|c|}
\hline \multirow[b]{2}{*}{ Parameter } & \multirow[b]{2}{*}{ Satuan } & \multicolumn{6}{|c|}{ Lokasi Pengambilan Sampel } & \multicolumn{4}{|c|}{ Baku Mutu Air } \\
\hline & & Titik I & Titik II & Titik III & Titik IV & Titik V & Titik VI & Kelas I & $\begin{array}{c}\text { Kelas } \\
\text { II }\end{array}$ & $\begin{array}{c}\text { Kelas } \\
\text { III }\end{array}$ & $\begin{array}{c}\text { Kelas } \\
\text { IV }\end{array}$ \\
\hline TSS & $\mathrm{mg} / \mathrm{l}$ & 28 & 34 & 44 & 46 & 48 & 64 & 50 & 50 & 400 & 400 \\
\hline $\mathrm{pH}$ & & 7.6 & 7.7 & 7.8 & 7.7 & 7.6 & 7.5 & $6-9$ & $6-9$ & $6-9$ & $6-9$ \\
\hline BOD & $\mathrm{mg} / \mathrm{l}$ & 7.82 & 5.75 & 8.67 & 18.39 & 22.9 & 27 & 2 & 3 & 6 & 12 \\
\hline COD & $\mathrm{mg} / \mathrm{l}$ & 13.42 & 15.79 & 38.67 & 35.52 & 44.99 & 56.04 & 10 & 25 & 50 & 100 \\
\hline DO & $\mathrm{mg} / \mathrm{l}$ & 4.33 & 3.95 & 1.99 & 0.77 & 1.5 & 0.52 & 6 & 4 & 3 & 0 \\
\hline $\begin{array}{l}\text { Total fosfat } \\
\text { sbg P }\end{array}$ & $\mathrm{mg} / \mathrm{l}$ & $<0.001$ & $<0.001$ & $<0.001$ & $<0.001$ & $<0.001$ & $<0.001$ & 0.2 & 0.2 & 1 & 5 \\
\hline Khromium & $\mathrm{mg} / \mathrm{l}$ & $<0.010$ & $<0.010$ & $<0.010$ & $<0.010$ & $<0.010$ & $<0.010$ & - & - & - & - \\
\hline
\end{tabular}

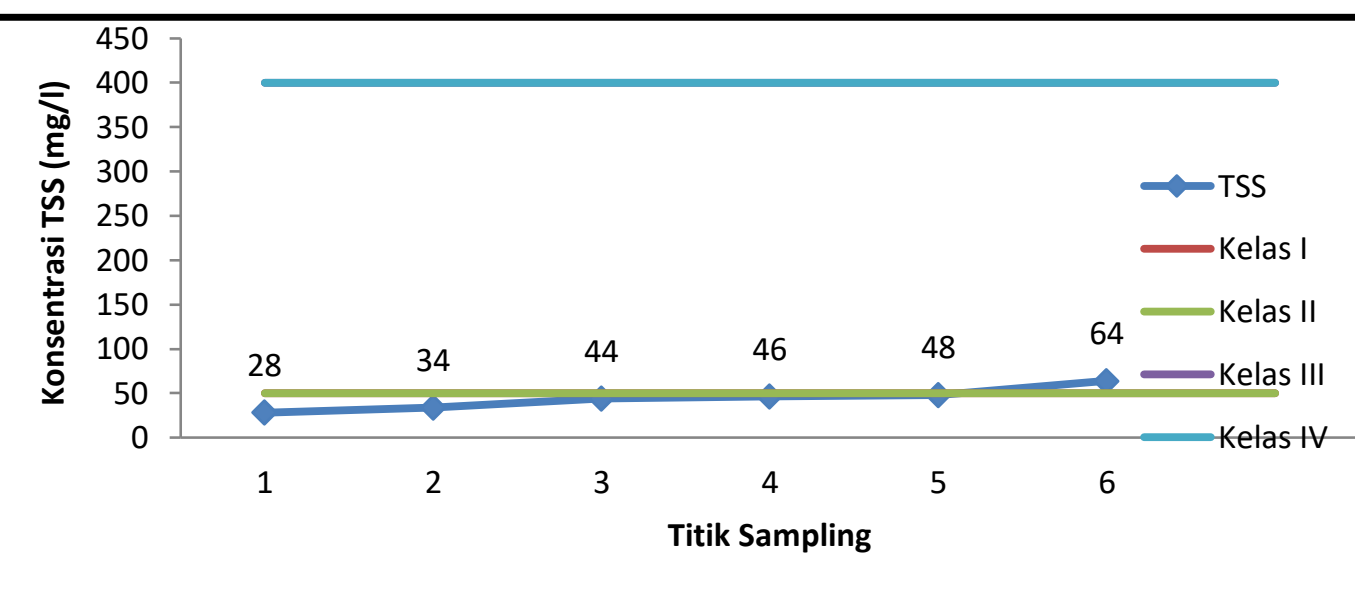

Gambar 3. Konsentrasi TSS di Sungai Kupang

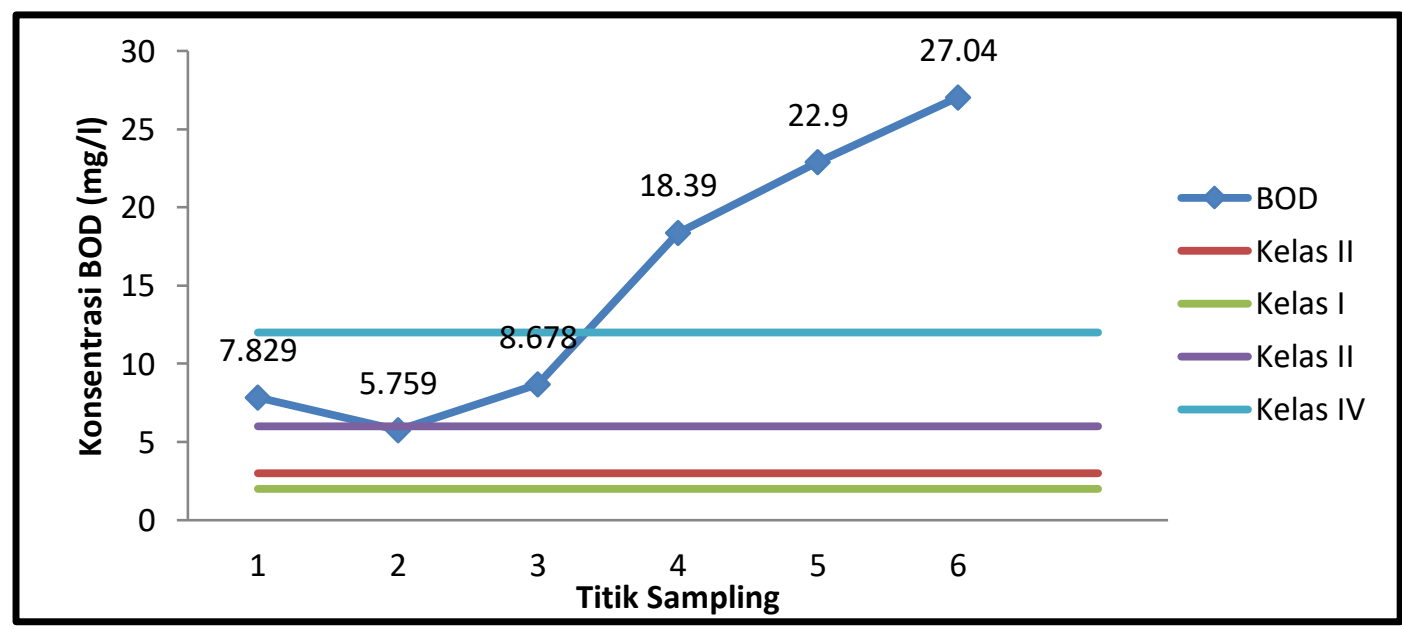

Gambar 4. Konsentrasi BOD di Sungai Kupang 


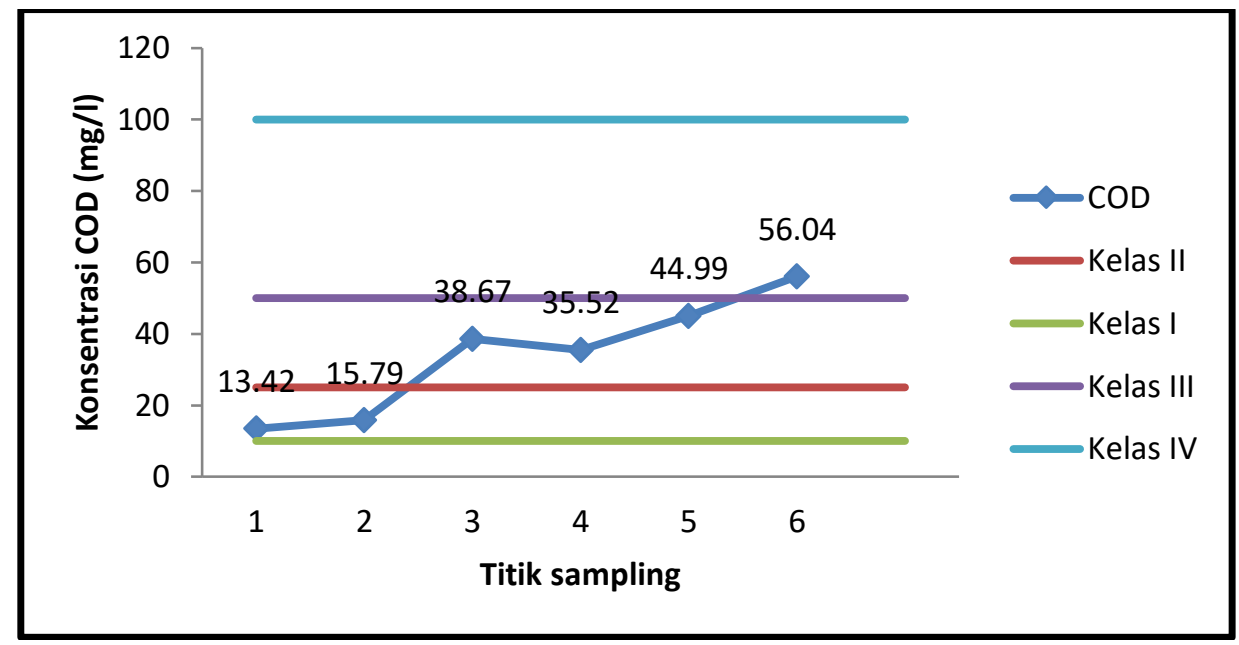

Gambar 5. Konsentrasi COD di Sungai Kupang

Dari hasil analisis kualitas air diatas menunjukkan bahwa konsentrasi BOD pada semua titik telah melebihi baku mutu kelas I, II, dan III, sedangkan pada titik 4, 5, dan 6 telah melebihi baku mutu kelas IV. Nilai konsentrasi BOD terendah adalah pada titik 2 sebesar $5,75 \mathrm{mg} / \mathrm{l}$, sedangkan nilai BOD tertinggi adalah pada titik 6 sebesar $27 \mathrm{mg} / \mathrm{l}$. jika dilihat dari hasil anlisis kualitas air di atas konsentrasi BOD dan COD dari hulu ke hilir semakin meningkat, hal ini disebabkan dari kegiatan permukiman. Bahan organik tersusun dari senyawa karbon, hidrogen, oksigen dan ada pula yang mengandung senyawa nitrogen (Metcalf and Eddy, 1979). Bahan buangan organik umumnya berupa limbah yang dapat membusuk atau terdegradasi oleh mikroorganisme, sehingga bila dibuang ke perairan akan menaikkan BOD (Rahmawati, 2011). Kenaikan kandungan BOD diduga karena selama perjalanannya aliran air yang di mulai dari hulu hingga hilir banyak menerima limbah buangan.

Pada dekomposisi bahan organik dalam jumlah besar dalam perairan akan menyerap oksigen dalam air sehingga menurunkan jumlah oksigen terlarut (DO). Pada titik VI BOD sebesar 27,04 mg/l sedangkan niali DO sebesar $0.52 \mathrm{mg} / \mathrm{l}$. Konsentrasi COD dari titik 1 sampai tiik 6 telah melebihi baku mutu kelas I. konsentrasi COD pada titik 1 sebesar 13,42 mg/l, titik 2 sebesar 17,79 mg/l, sedangkan pada titik 3, 4, 5 dan 6 telah melebihi baku mutu kelas II. Nilai konsentrasi COD tertinggi adalah pada titik 6 sebesar 56,04 mg/l dan telah melebihi baku mutu kelas III. Sedangkan konsentrasi COD terendah adalah pada titik 1 sebesar 13,42 mg/l. Menurut UNESCO, WHO/UNEP (1992) dalam yuliastuti (2011) nilai COD pada perairan yang tidak tercemar biasanya kurang dari $20 \mathrm{mg} / \mathrm{l}$. Pada konsentrasi TSS, pH, DO, fosfat dan khromium telah memenuhi baku mutu.

\subsection{Perhitungan indeks pencemaran}

Pada perhitungan indeks pencemaran dalam penelitian ini berdasarkan pada 6 titik dan parameter yang telah ditentukan yaitu, TSS, BOD, COD, DO, pH, Phospat dan Khromium.

Dari perhitungan status mutu air Sungai Kupang untuk kelas II, indeks pencemaran (IP) pada titik 1 dan 2 masih dalam kategori kondisi baik. Sedangkan pada titik 3, 4, 5, dan 6 sudah dalam kategori cemar ringan. Nilai indeks pencemaran tertinggi adalah pada titik VI dan indeks pencemaran terendah adalah pada titik 2 .

Dan untuk kriteria kelas I pada semua titik masuk dalam kategori cemar ringan. Sementara status mutu air pada kelas III dan IV masuk dalam kategori kondisi baik.

Tabel 5 Hasil Beban Pencemaran Sungai Kupang

\begin{tabular}{crrr}
\hline & \multicolumn{3}{c}{ Beban Pencemaran (Kg/Hari) } \\
\cline { 2 - 4 } Titik Lokasi & \multicolumn{1}{c}{ TSS } & \multicolumn{1}{c}{ BOD } & \multicolumn{1}{c}{ COD } \\
\hline 1 & $2.878,85$ & 805,05 & $1.379,79$ \\
2 & 999,00 & 169,00 & 464,00 \\
3 & $6.842,88$ & $1.349,91$ & $6.013,96$ \\
4 & $1.987,20$ & 794,45 & $1.534,46$ \\
5 & $2.488,32$ & $1.187,14$ & $2.332,28$ \\
6 & $5.474,30$ & $2.312,89$ & $4.793,44$ \\
\hline Total & $\mathbf{2 0 . 6 7 0 , 3 3}$ & $\mathbf{6 . 6 1 8 , 6 4}$ & $\mathbf{1 6 . 5 1 7 , 7 8}$ \\
\hline
\end{tabular}

\subsection{Beban pencemaran}

Berikut adalah tabel hasil analisis beban pencemaran dari masing-masing titik pengambilan sampel ditampilkan pada tabel dibawah ini.

Dari hasil perhitungan grafik diatas menunjukkan bahwa beban pencemaran Sungai Kupang dari hulu ke hilir mengalami peningkatan, untuk beban pencemaran konsentrasi TSS adalah sebesar 20.670,334 kg/hari, sedangkan konsentrasi COD adalah sebesar 16.517,777 kg/hari, dan konsentrasi BOD yaitu sebesar $6.618,643 \mathrm{~kg} / \mathrm{hari}$. Beban pencemaran konsentrasi COD dan TSS tinggi dikarenakan adanya aktifitas yang membuang limbah ke badan Sungai Kupang seperti aktifitas industri dan 
permukiman. Adanya beban cemaran sungai yang disebabkan oleh sumber-sumber pencemar di sekitar sungai Kupang yang memberikan kontribusi beban cemaran cukup tinggi merupakan salah satu indikasi adanya penurunan kualitas lingkungan di sekitar sungai Kupang dan adanya perubahan tata guna lahan yang mengakibatkan beban cemaran semakin tinggi.

\subsection{Permodelan Qual2Kw}

Agar model dapat digunakan untuk strategi pengelolaan pencemaran sungai, maka pertama-tama adalah perlu dilakukan uji validasi untuk mengetahui apakah data model dan data lapangan tidak memiliki perbedaan nilai yang signifikan. Uji yang dilakukan antara nilai model dan nilai lapangan dilakukan dengan metode Chi-Square.

\subsection{Perhitungan che square TSS Model dengan TSS Lapangan}

Perhitungan che square TSS Model dengan TSS Lapangan dapat dilihat pada tabel berikut.

Tabel 6. Uji Kecocokan TSS Model dengan TSS Lapangan

\begin{tabular}{|c|c|c|c|c|c|}
\hline $\begin{array}{l}\text { Reach } \\
\text { Label }\end{array}$ & $\begin{array}{l}\text { Titik } \\
\text { Sampling }\end{array}$ & $\begin{array}{l}\text { Jarak } \\
(\mathrm{Km})\end{array}$ & $\begin{array}{l}\text { Nilai } \\
\text { Lapangan } \\
(\mathrm{mg} / \mathrm{l})\end{array}$ & $\begin{array}{l}\text { Model } \\
\text { (mg/l) }\end{array}$ & $\begin{array}{l}\mathrm{X}^{2} \\
\text { Hitung }\end{array}$ \\
\hline Reach 1 & Titik 1 & 8,02 & 28,00 & 28,00 & 0,000 \\
\hline \multirow[t]{2}{*}{ Reach 2} & Titik 2 & 7,24 & 34,00 & 31,33 & 0,227 \\
\hline & Titik 3 & 4,46 & 44,00 & 39,09 & 0,617 \\
\hline \multirow{3}{*}{ Reach 3} & Titik 4 & 1,58 & 46,00 & 44,53 & 0,048 \\
\hline & Titik 5 & 0,96 & 48,00 & 52,72 & 0,422 \\
\hline & Titik 6 & 0 & 64,00 & 62,33 & 0,045 \\
\hline \multicolumn{6}{|c|}{ Jumlah nilai $x^{2}$} \\
\hline \multicolumn{2}{|c|}{ Hitung TSS } & \multicolumn{4}{|c|}{1,359} \\
\hline \multicolumn{6}{|c|}{$\alpha 95 \%, n$} \\
\hline \multicolumn{2}{|c|}{6} & \multicolumn{2}{|c|}{$x^{2}$ Tabel } & 1,635 & \\
\hline \multicolumn{2}{|c|}{$\mathrm{x}^{2}$ Hitung $<\mathrm{x}^{2}$ Tabel } & & & $\begin{array}{c}\text { Model } \\
\text { diterima }\end{array}$ & \\
\hline
\end{tabular}

Pada Uji kecocokan antara TSS lapangan dengan TSS model menunjukkan bahwa model dapat diterima dimana nilai $\mathrm{x}^{2}$ hitung lebih rendah dari pada $\mathrm{x}^{2}$ tabel.

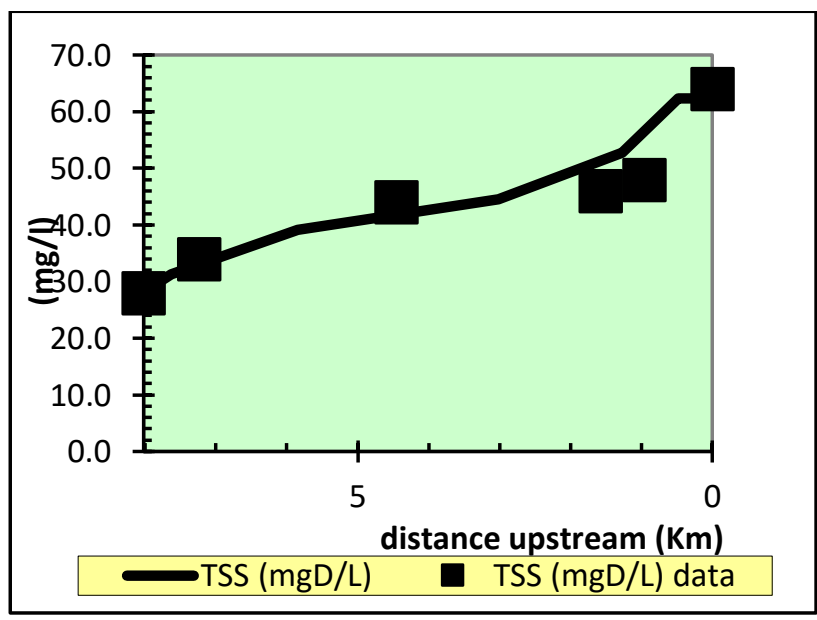

Gambar 6.Grafik perbandingan TSS Model dan TSS Lapangan dengan Qual2Kw

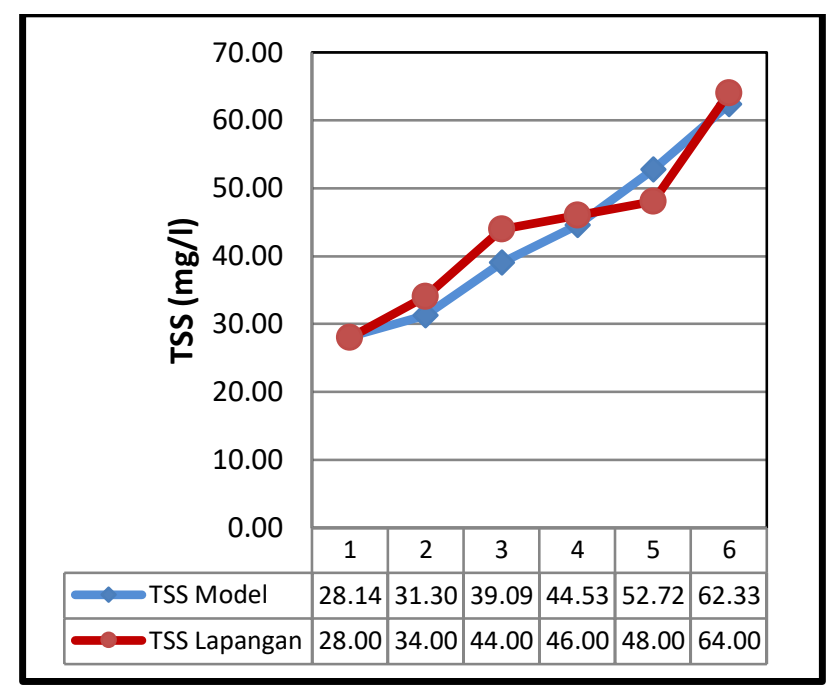

Gambar 7.Perbandingan TSS Model dan TSS Lapangan

\subsection{Perhitungan che square BOD Model dengan BOD Lapangan}

Perhitungan che square BOD Model dengan BOD Lapangan dapat dilihat pada tabel berikut.

Tabel 7. Uji Kecocokan BOD Model dengan BOD Lapangan

\begin{tabular}{|c|c|c|c|c|c|}
\hline $\begin{array}{l}\text { Reach } \\
\text { Label }\end{array}$ & $\begin{array}{l}\text { Titik } \\
\text { Sampling }\end{array}$ & $\begin{array}{l}\text { Jarak } \\
(\mathrm{Km})\end{array}$ & $\begin{array}{l}\text { Nilai } \\
\text { Lapangan } \\
(\mathrm{mg} / \mathrm{l})\end{array}$ & $\begin{array}{l}\text { Model } \\
(\mathrm{mg} / \mathrm{l})\end{array}$ & $\begin{array}{l}\mathrm{X}^{2} \\
\text { Hitung }\end{array}$ \\
\hline Reach 1 & Titik 1 & 8,02 & 7,83 & 7,83 & 0,000 \\
\hline \multirow[t]{2}{*}{ Reach 2} & Titik 2 & 7,24 & 5,76 & 6,17 & 0,027 \\
\hline & Titik 3 & 4,46 & 8,68 & 10,03 & 0,182 \\
\hline \multirow[t]{3}{*}{ Reach 3} & Titik 4 & 1,58 & 18,39 & 16,37 & 0,249 \\
\hline & Titik 5 & 0,96 & 22,90 & 18,76 & 0,913 \\
\hline & Titik 6 & 0 & 27,04 & 26,13 & 0,031 \\
\hline \multicolumn{6}{|c|}{ Jumlah nilai $x^{2}$} \\
\hline \multicolumn{2}{|l|}{$\begin{array}{l}\alpha 95 \%, \\
\text { n 6, }\end{array}$} & \multicolumn{2}{|c|}{$\mathrm{x}^{2}$ Tabel } & \multicolumn{2}{|c|}{1,635} \\
\hline \multicolumn{4}{|c|}{$\mathrm{x}^{2}$ Hitung $<\mathrm{x}^{2}$ Tabel } & diter & \\
\hline
\end{tabular}

Pada uji kecocokan antara BOD Model dengan BOD Lapangan menunjukkan bahwa model dapat diterima dimana nilai $\mathrm{x}^{2}$ hitung lebih rendah dari pada $\mathrm{x}^{2}$ tabel.

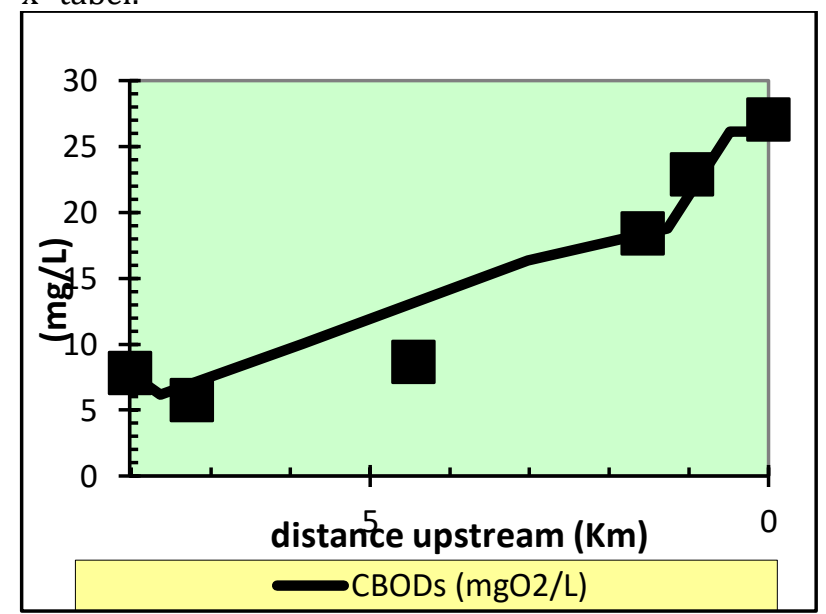

Gambar 8.Grafik perbandingan BOD Model dan BOD Lapangan dengan Qual2 Kw 


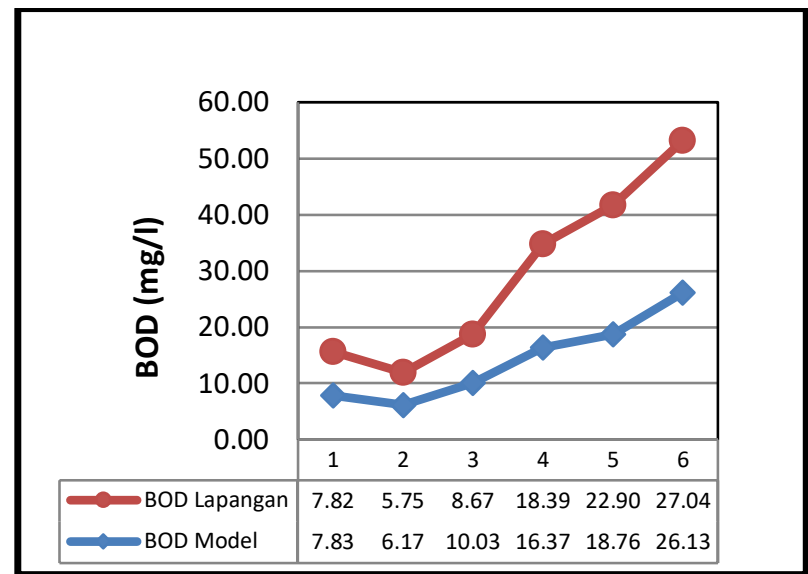

Gambar 9.Grafik konsentrasi BOD Model dengan BOD Lapangan

\subsection{Perhitungan che square COD Model dengan COD Lapangan}

Perhitungan che square COD Model dengan COD Lapangan dapat dilihat pada tabel sebagai berikut.

Tabel 8. Uji Kecocokan BOD Model dengan BOD Lapangan

\begin{tabular}{|c|c|c|c|c|c|}
\hline $\begin{array}{l}\text { Reach } \\
\text { Label }\end{array}$ & $\begin{array}{l}\text { Titik } \\
\text { Sampling }\end{array}$ & $\begin{array}{l}\text { Jarak } \\
(\mathrm{Km})\end{array}$ & $\begin{array}{l}\text { Nilai } \\
\text { Lapangan } \\
(\mathrm{mg} / \mathrm{l})\end{array}$ & $\begin{array}{l}\text { Model } \\
(\mathrm{mg} / \mathrm{l})\end{array}$ & $\begin{array}{l}\mathrm{X}^{2} \\
\text { Hitung }\end{array}$ \\
\hline \multirow[t]{2}{*}{ Reach 1} & Titik 1 & 8,02 & 13,42 & 13,42 & 0,000 \\
\hline & Titik 2 & 7,24 & 15,79 & 16,75 & 0,055 \\
\hline \multirow[t]{2}{*}{ Reach 2} & Titik 3 & 4,46 & 38,67 & 33,57 & 0,744 \\
\hline & Titik 4 & 1,58 & 35,52 & 34,73 & 0,018 \\
\hline \multirow[t]{2}{*}{ Reach 3} & Titik 5 & 0,96 & 44,99 & 43,30 & 0,066 \\
\hline & Titik 6 & 0 & 56,04 & 55,10 & 0,016 \\
\hline \multicolumn{2}{|c|}{ Hitung TSS } & & & & 0,929 \\
\hline \multicolumn{2}{|c|}{$\begin{array}{l}\alpha 95 \%, n \\
6,\end{array}$} & $x^{2}$ & & & \\
\hline \multicolumn{2}{|c|}{$\mathrm{x}^{2}$ Hitung $<\mathrm{x}^{2}$ Tabel } & & \multicolumn{3}{|c|}{ Model diterima } \\
\hline
\end{tabular}

Pada uji kecocokan antara COD Model dengan COD Lapangan menunjukkan bahwa model dapat diterima dimana nilai $\mathrm{x}^{2}$ hitung lebih rendah dari pada $\mathrm{x}^{2}$ tabel.

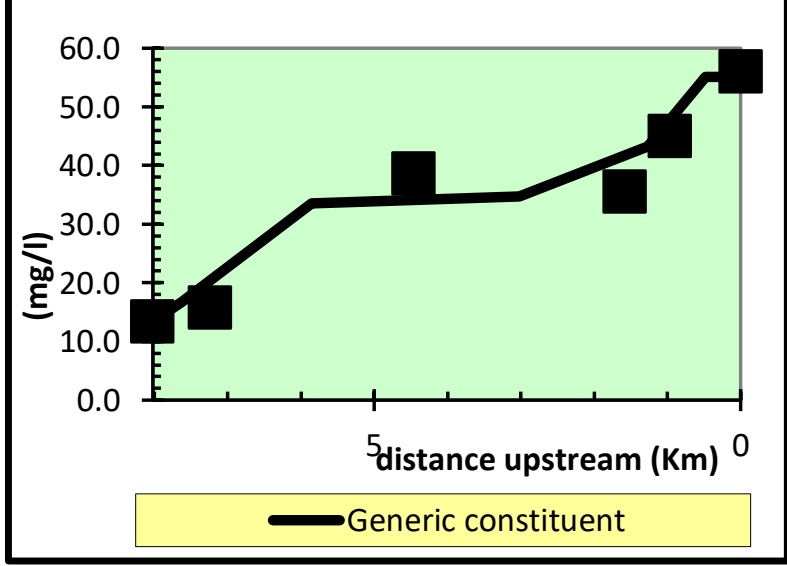

Gambar 10. Grafik perbandingan COD Lapangan dengan Qual2Kw

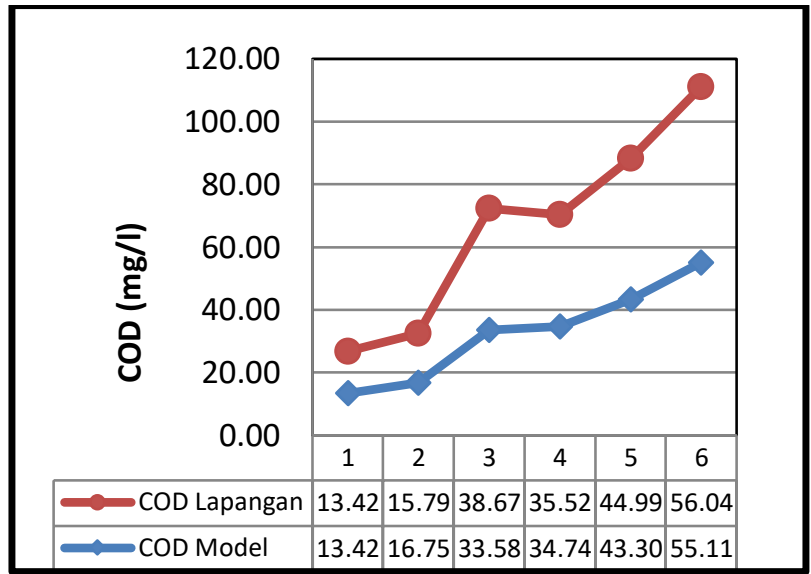

Gambar 11. Grafik konsentrasi COD Model dengan COD Lapangan

Pada hasil grafik permodelan konsentrasi TSS, BOD dan COD dari hulu hingga hilir dengan Program QUAL2Kw. menunjukan bahwa TSS, BOD, dan COD model dengan TSS, BOD, dan COD hasil lapangan memiliki pola grafik yang sama. Dari hasil grafik diatas terjadi peningkatan TSS dari hulu ke hilir, begitu juga dengan konsentrasi BOD dan COD, semakin menuju ke hilir sungai konsentrasi TSS , BOD dan COD semakin tinggi.

\subsection{Daya Tampung Beban Pencemaran}

Perhitungan daya tampung beban pencemaran TSS, BOD dan COD di badan Sungai Kupang, terlebih dahulu dilakukan dengan menghitung beban pencemaran di sungai dengan baku mutu kualitas air kelas I, II, III dan IV pada masing-masing konsentrasi, kemudian dikurangi beban cemar di sungai.

Konsentrasi beban pencemar apabila berada diatas garis baku mutu dan nilai daya tampung beban cemar masih positif (+) maka beban cemar menunjukkan bahwa bahan pencemar yang masuk ke sungai masih memenuhi daya tampung beban cemar sungai. Sebaliknya apabila beban pencemar berada dibawah garis baku mutu beban cemar dan nilai daya tampung beban cemar sudah negatif (-) maka bahan pencemar yang masuk ke badan sungai telah melebihi kemampuan daya tampung beban cemar sungai.

Berikut adalah tabel hasil perhitungan daya tampung beban pencemaran konsentrasi TSS dari masing-masing titik lokasi penelitian.

Tabel 9.Hasil Perhitungan DTBP TSS

\begin{tabular}{llllll}
\hline & \multicolumn{3}{c}{$\begin{array}{c}\text { Beban } \\
\text { Pencemaran } \\
\text { Kg/Hari) }\end{array}$} & \multicolumn{3}{c}{$\begin{array}{c}\text { Daya Tampung Beban } \\
\text { Pencemaran (Kg/Hari) }\end{array}$} \\
\cline { 2 - 6 } Titik & \multicolumn{1}{c}{ TSS } & \multicolumn{1}{c}{ Kelas I } & Kelas II & Kelas III & Kelas IV \\
\hline 1 & 2.878 & 261,00 & 2261,00 & 38247,00 & 38247,15 \\
2 & 999,00 & 469,00 & 469,00 & 176,216 & 176,216 \\
3 & 6.842 & 933,00 & 933,00 & 55365,12 & 55365,12 \\
4 & 1.987 & 172,00 & 172,00 & 15292,80 & 15292,80 \\
5 & 2.488 & 103,00 & 103,00 & 18247,68 & 18247,68 \\
6 & 5.474 & $-1198,00$ & $-1198,00$ & 28739,70 & 28739,70 \\
\hline
\end{tabular}


Berdasarkan hasil perhitungan daya tampung beban pencemaran TSS diatas, menunjukkan bahwa daya tampung dari Titik 1 - Titik $5(\mathrm{Km} \pm$ 8,02 - Km \pm $0,96)$ untuk kelas I dan kelas II masih memenuhi baku mutu beban pencemaran sedangkan pada titik 6 (Km \pm 0) sudah melebihi baku mutu daya tampung Sungai Kupang, agar Sungai Kupang dapat di rekomendasikan pada kualitas air kelas II sesuai PP No. 82 tahun 2001, maka pada titik 6 harus dilakukan pengurangan beban pencemar TSS sebesar 1198,00 $\mathrm{Kg} /$ hari.

Sementara pada hasil perhitungan daya tampung beban pencemaran TSS, menunjukkan bahwa daya tampung di semua titik lokasi untuk kelas III dan IV masih memenuhi baku mutu beban pencemaran.

Hasil perhitungan daya tampung beban pencemaran konsentrasi BOD dari masing-masing titik lokasi penelitian disajikan pada tabel. 12 sebagai berikut.

Tabel 10. Hasil Perhitungan DTBP BOD

\begin{tabular}{llllll}
\hline & $\begin{array}{l}\text { Beban } \\
\text { Pencemaran } \\
\text { Titik }\end{array}$ & \multicolumn{3}{c}{$\begin{array}{l}\text { Daya Tampung Beban } \\
\text { Pencemaran (Kg/Hari) }\end{array}$} \\
\cline { 2 - 6 } & BOD & Kelas I & Kelas II & Kelas III & Kelas IV \\
\hline 1 & 805,05 & $-599,42$ & $-496,60$ & $-188,15$ & 428,74 \\
2 & 169,205 & $-110,453$ & $-81,077$ & 7,051 & 183,307 \\
3 & 1349,91 & $-1.038,00$ & $-883,35$ & $-416,79$ & 516,33 \\
4 & 794,45 & $-708,00$ & $-665,848$ & $-535,25$ & $-276,05$ \\
5 & 1187,14 & $-1.083,00$ & $-1.032,00$ & $-876,10$ & $-565,06$ \\
6 & 2312,89 & $-2141,82$ & $-2056,28$ & $-1799,67$ & $-1286,46$ \\
\hline
\end{tabular}

Dari hasil tabel dan grafik diatas menunjukkan bahwa untuk kelas I, dari titik 1 - 6 telah melebihi daya tampung beban pencemaran Sungai Kupang. Sedangkan untuk kelas II juga sudah melebihi baku mutu daya tampung sungai.

Sementara untuk kelas III pada titik 2 (Km \pm $7,24)$ masih memenuhi baku mutu, sedangkan titik 1 , 3, 4, 5 dan 6 sudah melebihi baku mutu. Dan untuk kelas IV dari titik 1 - 3 masih memenuhi baku mutu daya tampung, sedangkan titik 4 - 6 sudah melebihi baku mutu, dan harus dilakukan pengurangan beban pencemaran. Untuk itu diperlukan upaya pengelolaan sungai untuk mengembalikan kualitas Sungai Kupang agar di rekomendasikan ke kelas II, yaitu dengan melakukan penurunan beban cemar pada semua titik sampling.

Hasil perhitungan daya tampung beban pencemaran konsentrasi COD dari masing-masing titik lokasi penelitian disajikan pada tabel .4.16 dibawah ini.

Dari hasil tabel dan grafik diatas menunjukkan bahwa di sepanjang sungai Kupang untuk kelas I, dari titik 1 - 6 telah melebihi daya tampung beban pencemaran sedangkan untuk kelas II pada titik 1 dan 2 masih memenuhi baku mutu beban pencemaran, dan pada titik 3 - 6 sudah melebihi baku mutu daya tampung sungai. maka harus dilakukan pengurangan pencemaran, yaitu pada titik 3 harus dilakukan pengurangan beban cemar COD sebesar $2126 \mathrm{Kg} / \mathrm{hari}$, sedangkan pada titik 4 pengurangan beban cemar COD sebesar 454,46 Kg/hari, pada titik 5 dilakukan pengurangan beban cemar COD sebesar 372,28 $\mathrm{Kg} / \mathrm{hari}$, dan pada titik 6 pengurangan beban cemar COD adalah sebesar 2655,44 Kg/hari.

Tabel 11. Hasil Perhitungan DTBP COD

\begin{tabular}{clllll}
\hline & $\begin{array}{l}\text { Beban } \\
\text { Pencemaran } \\
\text { (Kg/Hari) }\end{array}$ & \multicolumn{4}{c}{$\begin{array}{l}\text { Daya Tampung Beban } \\
\text { Pencemaran (Kg/Hari) }\end{array}$} \\
\hline Titik & COD & Kelas I & Kelas II & Kelas III & Kelas IV \\
\hline 1 & $1.379,79$ & $-351,79$ & 1190,21 & 3761,21 & 8902,21 \\
2 & 464,847 & $-170,087$ & 271,553 & 1.005 & 2.474 \\
3 & $6.013,96$ & -4.462 & -2.126 & 1762,04 & 9538,04 \\
4 & 1534,46 & -1.102 & $-454,46$ & 625,54 & 2785,54 \\
5 & 2332,28 & -1.814 & $-372,28$ & 259,72 & 2851,72 \\
6 & 4793,44 & $-3938,44$ & $-2655,44$ & $-516,44$ & 3760,56 \\
\hline
\end{tabular}

Sementara untuk kelas III pada titik 1 - 5 masih dibawah baku mutu, sedangkan titik 6 sudah di atas baku mutu. Dan untuk kelas IV dari titik 1 sampai dengan titik 6 masih dibawah baku mutu, dan masih memenuhi daya tampung beban pencemaran sungai kupang. agar dapat memenuhi baku mutu daya tampung beban pencemaran untuk kelas II.

Jika sumber pencemar di sekitar Sungai Kupang yang air limbahnya mengalir atau dibuang langsung ke badan sungai dan tanpa diolah terlebih dahulu, maka akan menambah beban cemaran sungai, yang berakibat turunnya daya tampung beban cemar Sungai Kupang. Besarnya limbah cemaran ini apabila tidak dikendalikan akan mengakibatkan turunnya kualitas air yang pada akhirnya akan mengganggu ekosistem perairan di Sungai Kupang.

\subsection{Upaya pengelolaan Sungai Kupang ditinjau dari Aspek Lingkungan}

\section{- Segmen I}

Jika dilihat dari beban pencemaran pada lokasi ini, untuk upaya rekomendasi pengelolaan adalah melakukan pengurangan beban pencemaran yaitu dengan melibatkan masyarakat dalam pengelolaan lingkungan sungai, dan perlu meningkatkan efektifitas pengelolaan dan manajemen IPAL yang lebih baik, dengan lebih melibatkan peran serta masyarakat dalam teknis pengelolaannya.

- Segmen II

Rekomendasi dalam upaya pengelolaan pada segmen ini adalah berawal dari kesadaran masyarakat tentang pengelolaan sampah rumah tangga serta tidak membuang sampah ke badan Sungai Kupang. Jika dilihat dari penggunaan lahan pada segmen ini adalah pemukiman padat penduduk. Agar beban pencemaran pada segmen ini tidak melebihi baku mutu daya tampung kelas II, maka masyarakat perlu menjaga kebersihan lingkungan dan tidak membuang sampah sembarang ke badan sungai serta memanfaatkan dan memelihara dengan baik fasilitas pengolahan limbah IPAL komunal yang sudah ada. 


\section{- Segmen III}

Untuk rekomendasi upaya pengelolaan pada segmen ini yaitu perlu adanya meningkatkan penegakan hukum kepada industri atau pelaku lain yang terbukti mencemari sungai dengan cara kerjasama yang aktif dalam pemantauan dan pengawasan pada pihak industri, dengan melibatkan elemen masyarakat. Meningkatkan pemantauan rutin kualitas sungai dan memetakan sumber-sumber pencemar potensial. Jika ditinjau dari aspek lingkungan pada segmen ini perlu adanya pengawasan dan pengelolaan lingkungan terhadap industri kecil dan industri menengah serta kawasan pemukima nyang berpotensi mencemari sungai, seperti efektifitas pengelolaan IPAL komunal.

\section{KESIMPULAN DAN SARAN 4.1 Kesimpulan}

Dari hasil penelitian anlisis kualitas air Sungai Kupang dapat disimpulakan bahwa;

1. Kualitas air Sungai Kupang mengalami penurunan kualitas dari hulu ke hilir yang disebabkan oleh bahan organik.

2. Kondisi kualitas air Sungai Kupang berdasarkan status mutu air menunjukkan penurunan kualitas air dari hulu sampai ke hilir sungai, dimana pada bagian hilir telah tercemar ringan.

3. Dari hasil perhitungan beban pencemaran Sungai Kupang disimpulkan bahwa Beban pencemaran sungai Kupang dari hulu ke hilir mengalami peningkatan, untuk beban pencemaran konsentrasi TSS adalah sebesar 20.670,334 $\mathrm{kg} /$ hari, sedangkan konsentrasi COD adalah sebesar 16.517,777 kg/hari, dan konsentrasi BOD yaitu sebesar $6.618,643 \mathrm{~kg} / \mathrm{hari}$.

4. Untuk rekomendasi upaya pengelolaan Sungai Kupang yaitu; perlu adanya meningkatkan penegakan hukum kepada industri atau pelaku lain yang terbukti mencemari sungai, Meningkatkan pemantauan rutin kualitas sungai, memanfaatkan dan memelihara dengan baik fasilitas pengolahan limbah IPAL komunal yang sudah ada, melibatkan masyarakat dalam pengelolaan lingkungan sungai, dan perlu meningkatkan efektifitas pengelolaan dan manajemen IPAL yang lebih baik, dengan lebih melibatkan peran serta masyarakat dalam teknis pengelolaannya.

\subsection{Saran}

1. Konsentrasi BOD dan COD tergolong buruk untuk kelas II dan III, oleh karena itu perlu adanya pemantauan yang rutin dari instansi terkait terutama pada bagian hilir.

2. Pembuangan limbah domestik dan industri perlu di monitoring, agar tidak melewati standar baku mutu

\section{DAFTAR PUSTAKA}

Ardhani, D., 2014. Pengelolaan Sungai Batanghari Kabupaten Dharmayasa Berdasarkan Daya Tampung Beban Pencemaran Dengan Metode Qual2Kw. Thesis MIL. Undip.

Azwir. 2006. Analisa Pencemaran Air Sungai Tapung Kiri Oleh Limbah Industri Kelapa Sawit PT. Peputra Masterindo di Kabupaten Kampar. Tesis. MIL Undip.

Bahtiar, Ayi. 2007. Polusi Air Tanah Akibat Limbah Industri dan Rumah Tangga Serta Pencegahannya. Makalah Disampaikan Pada Pemberdayaan Masyarakat Tentang Konservasi Air Tanah di Wilayah Rancaekek Kabupaten Bandung.

Balai Pengelolaan Daerah Aliran Sungai Pemali Jratun. 2013. Gambaran Umum Daerah Aliran Sungai Kupang. BPDAS Pemali Jratun.

Deazy, 2011. Pengaruh Kegiatan Industri Terhadap Kualitas Air Sungai Diwak di Bergas Kabupaten Semarang dan upaya pengendalian pencemaran air sungai. Tesis MIL Universitas Diponegoro.

Effendi, Hefni. 2003. Telaah Kualitas Air : Bagi Pengelolaan Sumber Daya dan Lingkungan Perairan. Yogyakarta, Penerbit KANISIUS

Keputusan Menteri Negara Lingkungan Hidup Nomor 115 Tahun 2003 tentang Pedoman Penetuan Status Mutu Air.

Marfai, Aris dkk. 2004. Kajian Daya Tampung Sungai Gajahwong Terhadap Beban Pencemaran. Majalah Geografi Indonesia Vol 18 no 2.

Metcalf and Eddy. 1979. Wastewater Engineering Treatment and Reuse. Fourth Edition. Mc. Graw-Hill. New York

Peraturan Pemerintah Nomor 82 Tahun 2001 tentang Pengelolaan Kualitas Air dan Pengendalian Pencemaran Air.

Wiwoho. 2005. Model Identifikasi Daya Tampung Beban Cemaran Sungai Dengan QUAL2E. Tesis. Universitas Diponegoro. Semarang.

Yuliastuti, Etik. 2011. Kajian Kualitas Air Sungai Ngringo Karanganyar Dalam Upaya Pengendalian Pencemaran Air. Thesis MIL. Undip. 